\title{
AÇÕES AFIRMATIVAS, OBRIGATORIEDADE CURRICULAR DA EDUCAÇÃO DAS RELAÇÕES ÉTNICO-RACIAIS E FORMAÇÃO DOCENTE
}

\author{
Carla Beatriz Meinerz ${ }^{1}$ \\ Gládis Elise Pereira da Silva Kaercher ${ }^{2}$ \\ Graziela Oliveira Neto da Rosa ${ }^{3}$
}

\begin{abstract}
RESUMO: O artigo tematiza ações afirmativas de promoção da igualdade racial na formação docente, fundamentando a mudança curricular e a criação de disciplinas obrigatórias na graduação inicial como estratégia essencial na Educação Superior. Analisam-se registros documentais produzidos por estudantes cursistas de disciplina obrigatória de Educação e Relações Étnico-Raciais, articulados com dados da experiência de fiscalização por órgão de controle da exigência legal de implementação do artigo 26-A da Lei de Diretrizes e Bases da Educação Nacional (LDBEN) na Educação Básica do Rio Grande do Sul. Destacam-se as desestabilizações construídas ao longo dos processos de aprendizado inter-racial analisados, a partir dos princípios da branquitude, que hegemonizam a formação docente e compõem o ethos das instituições de ensino no Brasil.

Palavras-chave: Formação Docente. Ação Afirmativa. Educação. Relações Étnicoraciais. Fiscalização.
\end{abstract}

\section{AFFIRMATIVE ACTIONS, COMPULSORY CURRICULUM FOR ETHNIC-RACIAL RELATIONS EDUCATION AND TEACHER TRAINING}

ABSTRACT: The article focuses on affirmative actions to promote racial equality in teacher education, supporting the curricular change and the creation of mandatory subjects in initial graduation as a fundamental strategy in Higher Education. It analyzes documentary records produced by students taking the compulsory subject of Education and Ethnic-Racial Relations, articulated with data from the experience of inspection by a control agency of the legal requirement to implement Article 26-A/LDBEN in Basic Education in Rio Grande do Sul. It highlights the destabilization built during interracial learning processes, based on the principles of whiteness that dominate teacher education and make up the ethos of educational institutions in Brazil.

Keywords: Teacher Training. Affirmative Action. Education. Ethnic-racial Relations. Inspection.

1.Universidade Federal do Rio Grande do Sul - Faculdade de Educação - Porto Alegre (RS), Brasil. E-mail: carlameinerz@gmail.com 2.Universidade Federal do Rio Grande do Sul - Faculdade de Educação - Porto Alegre (RS), Brasil. E-mail: gskaaercher@gmail.com 3.Universidade Federal do Rio Grande do Sul - Faculdade de Educação - Porto Alegre (RS), Brasil. E-mail: grazielagi@gmail.com Editor de Seção: Salomão Barros Ximenes

Editores convidados: Nilma Lino Gomes, José Eustáquio Brito e Paulo Vinicius Baptista da Silva 


\section{ACCIONES AFIRMATIVAS, OBLIGATORIEDAD CURRICULAR DE LA EDUCACIÓN DE LAS RELACIONES ÉTNICO-RACIALES Y FORMACIÓN DOCENTE}

RESUMEN: El artigo tematiza acciones afirmativas de fomento de la igualdad racial en la formación docente, fundamentando la mudanza curricular y la creación de asignaturas obligatorias en la graduación inicial como estrategia fundamental en la Educación Superior. Analiza registros documentales producidos por estudiantes cursantes de materia obligatoria de Educación y Relaciones Étnico-Raciales, articulado con datos de experiencia de fiscalización por órgano de control de la exigencia legal de implementación del artículo 26-A/LDBEN en Educación Básica de Rio Grande do Sul. Destaca las desestabilizaciones construidas a lo largo de los procesos de aprendizaje interracial analizados, a partir de los principios de blanquitud que hegemonizan la formación docente y componen el ethos de las instituciones de enseñanza en Brasil.

Palabras-clave: Formación Docente. Acción Afirmativa. Educación. Relaciones Étnico-raciales. Fiscalización.

\section{Introdução}

A dimensão de nossa responsabilidade de mulheres e homens negros e dos não negros, particularmente de professores e pesquisadores, para com o combate ao racismo, sem dúvida alguma, é demarcada pelos sofrimentos impingidos aos negros - crianças, adolescentes, jovens e adultos - em todos os âmbitos da sociedade, inclusive nos estabelecimentos de ensino (SILVA, 2011, p. 121).

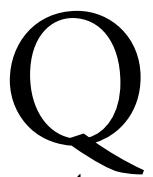

ual a nossa responsabilidade individual e institucional na luta antirracista no campo da Educação Superior? Como reagimos diante de episódios cotidianos de racismo? Para Grada Kilomba (2019), o termo cotidiano se refere ao fato de que experiências racistas não são pontuais. Segundo a autora, o racismo cotidiano "não é um 'ataque único' ou um 'evento discreto', mas sim [...] 'um padrão contínuo de abuso’ que se repete incessantemente ao longo da biografia de alguém” (KILOMBA, 2019, p. 80). A discriminação racial, assim como o racismo, "opera no indivíduo, na instituição e na estrutura social, mas é na esfera individual e na subjetividade que se expressa com mais força cotidianamente" (MEINERZ; SANTOS; PEREIRA, 2021, p.131).

Assim, uma disciplina curricular obrigatória, na graduação inicial, capaz de tratar desses episódios, com conhecimentos que possibilitem a compreensão e a superação pedagógica dos efeitos que eles produzem nos sujeitos envolvidos, é indispensável na formação de qualquer profissional da Educação Básica e Superior. Do ponto de vista das exigências legais, instituídas a partir do artigo 26-A da Lei de Diretrizes e Bases da Educação Nacional (LDBEN), criado pela Lei 10.639/03 (BRASIL, 2003), essa indispensabilidade e seu descumprimento devem ser fiscalizados, pois se trata de uma ação afirmativa no campo dos currículos escolares e universitários.

Compreendemos como ações afirmativas de promoção da igualdade racial na formação docente, no caso do Brasil, aquelas que "indagam a Universidade no que se refere às suas narrativas sobre o outro" (GOMES, 2020, p. 14). Elas se desdobram a partir de movimentos endógenos como a Primeira Marcha Zumbi contra 
o Racismo, pela Cidadania e pela Vida, realizada no dia 20 de novembro de 1995, em Brasília. Articulam-se com movimentos exógenos que se expressam na Terceira Conferência Mundial de Combate ao Racismo, Discriminação Racial, Xenofobia e Intolerância Correlata realizada em Durban, pela ONU (2001), com uma importante delegação brasileira. Os acordos internacionais decorrentes da Conferência de Durban estabelecem

[...] o reconhecimento da escravização como crime de lesa-humanidade e a demarcação do racismo num marco estrutural mais amplo [...], direcionado aos governos nacionais, com linhas estratégicas convocatórias de políticas públicas de reparação aos grupos mais afetados pela discriminação racial (MEINERZ; RAMÍREZ, 2018, p. 378).

Reiteramos que as políticas afirmativas resultam da agência do movimento negro e de intelectuais negros naquilo que Guimarães (2021) definirá como as modernidades negras, pensadas como processo histórico de luta por direitos, dentro dos partidos políticos, na esfera pública e na compreensão da realidade brasileira.

Sua execução na busca pela equidade racial ocorre em distintas modalidades, entre elas as cotas raciais em concursos de ingresso no mundo do trabalho e da educação, a demarcação de terras indígenas e quilombolas e, a que se destaca em nossa análise, a inserção de história e cultura indígena, africana e afrobrasileira nos currículos da Educação Básica e Superior.

Do ponto de vista das políticas públicas, o enfrentamento ao racismo institucional (ALMEIDA, 2018) se deu a partir das chamadas políticas de ação afirmativa, entendidas aqui como um conjunto de iniciativas do Estado visando a reparação dos efeitos do racismo. No campo da Educação, as ações afirmativas tomaram forma através de um ordenamento jurídico que terminou por colocar em privilegiado protagonismo os espaços escolares e sob a égide do currículo escolar, a responsabilidade por corrigir os apagamentos epistemológicos advindos do racismo. É na esteira desses movimentos que se coloca a análise de implementação de uma disciplina obrigatória na formação docente, capaz de promover a equidade racial no campo pedagógico, entrelaçando a função social da Universidade, como responsável pela formação inicial de professores que atuam na Educação Básica. Concordamos que a Lei 10.639/03 se caracteriza como ação afirmativa, numa configuração na qual "o Estado abandona a sua postura de neutralidade e passa a atuar para a concretização da igualdade material ou substantiva" (SILVA; RÉGIS; MIRANDA, 2018, p. 21).

A Educação das Relações Étnico-Raciais (ERER), como disciplina obrigatória nos currículos da graduação, é tema polêmico, concernente ao entendimento e à interpretação da função social da Educação Superior diante da obrigatoriedade legal das ações afirmativas de reparação histórica relativas ao racismo no nosso país. Exige uma compreensão do tratamento da política pública como demanda social consolidada através de ações afirmativas e do seu necessário cumprimento e fiscalização pelos tribunais competentes.

Metodologicamente, analisamos aqui registros documentais produzidos por estudantes cursistas de disciplina obrigatória de Educação e Relações Étnico-Raciais, no curso de Pedagogia da Universidade Federal do Rio Grande do Sul (UFRGS), articulados com dados da experiência de fiscalização da exigência legal de implementação do artigo 26-A da LDBEN na Educação Básica do Rio Grande do Sul. Para essa análise documental, seguimos os procedimentos éticos reconhecidos pela comunidade acadêmica. Atuamos na formação docente inicial na Educação Superior e Básica, assim como integramos um Grupo de Trabalho (GT) que, ao lado do Tribunal de Contas do Estado do Rio Grande do Sul (TCE/RS), fiscaliza a implementação do artigo 26-A da LDBEN. Nosso lugar de fala (RIBEIRO, 2017), portanto, é de integrantes de um coletivo que, além de assessorar o tribunal na fiscalização da implementação da Lei na Educação Básica, simultaneamente executa essa mesma exigência legal em nosso espaço de atuação na Educação Superior. 
A trajetória desse GT começa no final de 2012, quando o Ministério Público de Contas do Estado do Rio Grande do Sul (MPCRS) e a Rede Afro-Gaúcha de Profissionais do Direito realizaram uma amostra com 93 municípios acerca da aplicação do artigo 26-A em suas redes de ensino, buscando parceiros institucionais para construir uma análise diagnóstica e propositiva. Esse movimento evidenciou a inoperância dos gestores na implementação da Lei, suscitou a necessidade de fiscalização e orientou a constituição do GT 26- $\mathrm{A}^{1}$, na qualidade de monitoramento e assessoria de ações fiscalizatórias junto ao TCE/RS, como a elaboração de instrumentos de auditoria pública, formação e capacitação. O TCE é o órgão, partícipe do GT, responsável pela análise e fiscalização das ações dos gestores públicos municipais e estaduais, compreendido como espaço institucional que, por conseguinte, agrega na meta de efetivação das Diretrizes Curriculares Nacionais para a Educação das Relações Étnico-Raciais e para o Ensino de História e Cultura Afro-brasileira e Africana (DCNERER) e das ações afirmativas. A auditoria se dá pelo exame de aplicação de recursos orçamentários, formação e normatização nas unidades escolares e de gestão educativa no cumprimento do artigo 26-A da LDBEN. Registra-se que o TCE/RS é a primeira Corte de Contas a fiscalizar o cumprimento da Lei que determina o ensino de história e cultura afro-brasileira, africana e indígena nas redes de ensino.

Nesta escrita, somos duas docentes do magistério superior, uma negra e outra branca, acompanhadas de uma docente negra em atuação na escola básica, pesquisadora da fiscalização do artigo 26-A pelo TCE/ RS no mestrado acadêmico em Educação (ROSA, 2020). Dessa maneira, nossa pertença racial nos faz entremear olhares sobre as condições do cumprimento ou descumprimento dos preceitos legais. Assim, compreendemos que o cumprimento e a fiscalização da ação afirmativa no campo do currículo são imposição ética, moral e pedagógica, ainda que sejamos sabedoras dos desafios dessa implementação em espaços marcados pelo racismo institucional (ALMEIDA, 2018), pela colonização dos currículos (GOMES, 2012) e pela branquitude (BENTO, 2002). Reafirmamos a importância da formação docente inicial comprometida com o aprendizado inter-racial, para que os educadores possam adentrar as redes de ensino básico com conhecimento aprofundado necessário à sua atuação profissional, conforme as DCNERER (BRASIL, 2004).

Por aprendizado inter-racial, definimos o desenvolvimento da capacidade de direcionar positivamente as relações entre pessoas de diferente pertencimento étnico-racial, referenciando o texto das DCNERER:

[...] há necessidade, como já vimos, de professores qualificados para o ensino das diferentes áreas de conhecimentos e, além disso, sensíveis e capazes de direcionar positivamente as relações entre pessoas de diferente pertencimento étnico-racial, no sentido do respeito e da correção de posturas, atitudes, palavras preconceituosas. Daí a necessidade de se insistir e investir para que os professores, além de sólida formação na área específica de atuação, recebam formação que os capacite não só a compreender a importância das questões relacionadas à diversidade étnico-raciais, mas a lidar positivamente com elas e, sobretudo criar estratégias pedagógicas que possam auxiliar a reeducá-las (BRASIL, 2004, p. 17).

Por um tempo, houve uma falsa compreensão, reveladora dos mecanismos de atuação da branquitude e do racismo institucional presentes no campo das Instituições de Ensino Superior (IES), de que o artigo 26-A se impunha somente para a Educação Básica. Não há professores de Educação Básica sem formação na Educação Superior, portanto a ação afirmativa no currículo atinge de forma específica a função da formação docente inicial e continuada. Correlata a essa compreensão, estava a polêmica de que a ERER era transversal e não seria uma disciplina com conteúdo específico, pois seria compromisso de todos. Aprendemos que o que é compromisso de todos não é de ninguém, especialmente num país que não deseja encarar as mazelas de sua 
estrutura racista e racializada no passado e, sobretudo, no presente. A opção por uma disciplina obrigatória na formação docente de profissionais da Pedagogia na UFRGS, intitulada Educação e Relações Étnico-Raciais, regulamentada por meio da Comissão de Graduação do Curso, ocorreu no bojo dessas compreensões e aprendizagens em disputa.

O pressuposto básico do presente ensaio está no entendimento da ERER como ação afirmativa e de reparação histórica aos crimes de racismo no passado, impostos por brancos sobre negros e indígenas, que igualmente se encontra na assunção de nossa responsabilidade no presente.

A disciplina em questão se desenvolve numa universidade em solo sulino, com menos de um por cento de professores negros em seu corpo docente, e com maioria branca em seus pesquisadores e extensionistas, hegemonicamente operando na lógica do racismo estrutural (ALMEIDA, 2018) e de seus pactos narcísicos (BENTO, 2002). Maria Aparecida Silva Bento (2002) nos apoia para a reflexão acerca dos pactos narcísicos da branquitude. Assim, compreendemos que confundir currículo com seleção de conteúdo, sem a necessária positivação das brasilidades negras e indígenas, expressa um dos modos de operar da branquitude hegemônica no campo das Ciências Humanas e da própria Educação. Os impactos da positivação das histórias e práticas culturais negras e indígenas, assim como suas corporeidades nos espaços escolares e universitários, ressaltam os protagonismos e insurgências das ações afirmativas para a igualdade racial no campo da Educação, apontando para o fato de que tais reformulações curriculares não se dão apenas por vontades ou iniciativas individuais, mas demandam luta, enfrentamentos de grupos hegemônicos brancos, articulações e compromissos. Em suma, movimentos que explicitam, por fim, quem são aqueles que efetivamente estão posicionados nas trincheiras de luta cotidiana para promover a "quebra de desconfianças" apontada nas DCNERER, na direção de uma efetiva transformação das relações raciais.

Ressaltamos que a ERER possui uma dimensão cognitiva e uma relacional, quando pensada em proposição de formação docente. Na dimensão cognitiva, trata-se de uma política educacional de Estado com um projeto de sociedade não racista, cuja estratégia central é a descolonização dos currículos (GOMES, 2012) e dos conhecimentos acadêmicos e escolares. Na dimensão relacional, fundamenta-se no combate ao racismo, a partir do princípio da quebra de desconfianças e da crença de que temos muitas diferenças, mas necessitamos partilhar um projeto societário e humanitário comum. Esse projeto baseia-se na equidade racial e no respeito.

A reverberação da produção acadêmica sobre ERER pode ser observada a partir dos trabalhos compartilhados no Grupo de Trabalho 21 da Associação Nacional de Pós-Graduação e Pesquisa em Educação (ANPEd), intitulado a partir de 2009 "Educação e Relações Étnico-Raciais", criado oficialmente em 2001, então nomeado como "GT Estudos Afro-brasileiros e Educação". Tal produção foi compilada no estado da arte "Educação das Relações Étnico-raciais” (SILVA; RÉGIS; MIRANDA, 2018), organizado por pesquisadores do GT, que sistematizou e analisou a produção acadêmica sobre ERER entre os anos de 2003 e 2014, por meio da análise das teses e dissertações realizadas nos programas de pós-graduação stricto sensu em Educação e dos periódicos Qualis A e B na área da Educação. A sistematização evidenciou uma produção estável desde a homologação da Lei 10.639/03, com predominância nas investigações concentradas no Ensino Fundamental e desvelando a persistência do racismo e os desafios da educação antirracista, recomendando investimentos em formação docente. No que tange os temas de intersecção com nossa escrita, na categoria currículo apontou-se a necessidade de pesquisas acerca de "como as instituições de ensino superior nas diferentes áreas do conhecimento estão inserindo, ou não, nos seus currículos a temática?” (p. 666). Destacamos ainda a tendência de produção acadêmica em áreas específicas de formação docente, na perspectiva da ERER, como exemplos o ensino de história (PEREIRA; SILVA, 2021; COELHO, M.; COELHO, W., 2021); o ensino de Física (ALVES-BRITO, 2020) ou o ensino de Biologia (VERRANGIA, 2013). 
A seguir, apresentaremos brevemente o processo de implementação da disciplina nomeada Educação e Relações Étnico-Raciais, obrigatória e indispensável no currículo do curso de Pedagogia da UFRGS a partir de 2018, ofertada para alguns outros cursos desde 2019, compreendida como forma de implementação do artigo 26-A da LDBEN, criado pela Lei 10.639/03, considerada ação afirmativa no campo da Educação.

\title{
Caminhos de Implementação da ERER como Obrigatoriedade nos Currículos de Graduação da UFRGS
}

\begin{abstract}
Quando o alunado da UFRGS conhecerá a África, o berço da humanidade? E a riqueza da cultura indígena, quando receberá o mesmo (re)conhecimento da cultura de origem europeia? Parodiando os versos citados em Querela Brasileira, urge que a UFRGS conheça e valorize as culturas africana, afro-brasileira e indígena, para vencer a máxima que diz o Brasil não conhecer o Brasil e o Brasil nunca ter ido ao Brasil. Para se compreender um pouco da presença de pessoas negras durante toda a existência da UFRGS, mostrarei fragmentos de invasão e de ocupação da Universidade Federal do Rio Grande do Sul por pessoas negras (FONTOURA, 2017, p. 74).
\end{abstract}

Os questionamentos trazidos nesta epígrafe interpelam algumas das práticas e entendimentos mais correntes dentro de nossa universidade: aqueles que desvelam os impactos de nossos currículos, epistemologicamente brancos e eurocentrados, na efetiva formação dos docentes egressos do Ensino Superior. Em parte, isso diz respeito à composição do nosso quadro docente, majoritariamente branco, com epistemologias que hegemonizam o cerne de nossos currículos. Diz ainda de uma ausência de escuta às transformações havidas no campo da legislação educacional brasileira, decorrente das lutas dos movimentos sociais indígena e negro, na direção de materializar, também no campo dos currículos escolares, políticas de reparação. Maria Conceição Lopes Fontoura (2017) aponta que tal ausência anda lado a lado, historicamente, com a presença minoritária, mas extremamente potente e responsável pela transformação e democratização epistêmica e relacional da Universidade.

O currículo aqui não se resume ao conteúdo a ser ensinado, pois toda a construção de um currículo é feita em disputas de posições políticas e pedagógicas no campo da Educação e das áreas específicas do conhecimento científico, na intersecção com a sociedade. Estamos falando de interrogar o lugar da questão racial nos currículos, concretizado a partir da homologação da Lei 10.639/03, lembrando que, nessa indagação, igualmente questionamos o debate epistemológico sobre o diálogo interno e externo à ciência (GOMES, 2012). Aquilo que deve ser ensinado é regido pelo currículo, ou seja, pelo conjunto das variantes das prescrições legais, das edições materializadas em recursos didáticos e das práticas no cotidiano das instituições.

Pensando nessa perspectiva, apontamos a ERER como uma ação afirmativa que repara e corrige, dentro dos currículos escolares, o epistemicídio promovido historicamente na educação brasileira, que silenciou a história e a memória de negros e indígenas e produziu o entendimento de que o País e a episteme que conhecemos é fruto do trabalho branco. Para Sueli Carneiro (2005, p. 96), o epistemicídio é "o modus operandi do empreendimento colonial, da visão civilizatória que o informou". Ele produziu uma nação que realmente se entende nascida do esforço, da luta e da complacência branca, entendimento que se potencializa no sul do Brasil, com seu mito fundacional insistentemente reforçado como ligado à imigração alemã e italiana. 
Há, portanto, no cerne dessa ficção de nacionalidade, uma visão supremacista branca, produzida enormemente pela escola e pela universidade, reforçada pela mídia e por práticas estruturalmente racistas, que demandam urgente transformação curricular e didática, para fazer cumprir o ordenamento legal que regula a ERER. Essa transformação atravessa a validação do que deve ser conhecido e de quem deve disseminar os conhecimentos. Segundo Grada Kilomba (2019, p. 53),

[...] as estruturas de validação do conhecimento, que definem o que é conhecimento, que definem o que é erudição "de verdade" e "válida", são controlados por acadêmicas/os brancas/ os. Ambos, homens e mulheres, que declaram suas perspectivas como condições universais. Enquanto posições de autoridade e comando forem negadas às pessoas negras e à People of Color (PoC), a ideia sobre o que é ciência e erudição prevalece intacta, permanecendo "propriedade" exclusiva e inquestionável da branquitude. Portanto, o que encontramos na academia não é uma verdade objetiva científica, mas sim o resultado de relações desiguais de poder de "raça" (grifos da autora).

Observamos que essa estrutura de validação branca, acerca de quem deve ensinar e do que deve ser estudado, atravessa o debate a respeito da curricularização da ERER nas IES. Assim, um dos primeiros aspectos a observar, quanto à exigência da implantação da ERER nos currículos das licenciaturas, diz respeito ao fato de que, já em seu texto, o artigo 26-A produziu o peculiar movimento de ser lido apenas em parte, e não na totalidade de sua redação. Vejamos as letras da Lei:

$\$ 2^{\circ}$ Os conteúdos referentes à história e cultura afro-brasileira e dos povos indígenas brasileiros serão ministrados no âmbito de todo o currículo escolar, em especial nas áreas de educação artística e de literatura e história brasileiras. (BRASIL, 2004, grifo nosso)

Em que pese estar explícito que todos os campos do currículo deveriam se ocupar em inserir a "história e cultura afro-brasileira e dos povos indígenas", imputou-se aos cursos de História, Letras e Artes o efetivo cumprimento da "missão", eximindo-se as demais áreas de sua obrigação e, pior do que isso, mantendo-se as demais licenciaturas, dentro das universidades, distantes dessa discussão, logo, não imbricadas na construção desse novo projeto de nacionalidade trazido pela legislação que fundamenta a ERER no Brasil. Mas, afinal, quais ações contribuem para que esse equívoco convenientemente se mantenha dentro das licenciaturas? Que forças atuam para que gerações de professores sigam sendo formadas sem sequer o conhecimento dessas leis? Mais do que isso, até quando nossos colegas, professores universitários de maioria branca, seguirão indiferentes aos efeitos que suas omissões, e o perverso não cumprimento da Lei, provocam dentro das escolas?

Inconteste apontar que essa omissão produz uma conta, gera um passivo que só amplia os danos do racismo no Brasil: a inação docente, a implementação de reiteradas práticas educativas racistas segue produzindo, dentro das escolas e universidades, gerações de sujeitos que realmente creem na construção de uma nacionalidade e sociedade onde negros e indígenas são coadjuvantes, quiçá dispensáveis.

Ressaltamos que o racismo opera nos indivíduos e nas instituições, mas as subjetividades desestabilizadoras (GOMES, 2017) das pessoas negras e indígenas ensinam a romper com a supremacia branca, através de seu protagonismo, sua inteligência e sua força ancestral. As DCNERER, como resultantes dessas subjetividades desestabilizadoras, propõem um projeto de educação e de sociedade cujo estudo positivado das pessoas, histórias e culturas africanas, indígenas e afro-brasileiras é uma estratégia que se concretiza nos currículos e jamais se resume a um tema a ser dominado apenas por alguns. Acerca do 
debate entre ser disciplina específica ou tema transversal, é importante salientar que, nas DCNERER, encontramos a orientação sobre a forma que esse projeto atinge a todo o conhecimento construído nos espaços educativos, escolares, acadêmicos, entre outros. Porém, no Plano Nacional de Implementação da ERER, coloca-se como meta para as IES o oferecimento de disciplinas específicas de ERER para todos os cursos, prioritariamente as licenciaturas.

A aprovação da disciplina, nesse caso em análise, fez-se na circularidade de várias ações, como a de estudantes que produziram enquetes, por meio do diretório acadêmico, observando a solicitação da inserção das relações raciais como questão para o curso. Igualmente, houve a organização de um coletivo de docentes para formulação e defesa da criação da disciplina obrigatória, formada por professores de distintos departamentos da unidade, que em suas ações de pesquisa e extensão já estavam comprometidos com a ERER. Reiteramos que foi fundamental a participação de docentes e técnicos no GT 26-A, vinculado ao TCE/RS.

A disciplina Educação e Relações Étnico-Raciais está alocada no Departamento de Estudos Especializados (DEE), oferecida todo o semestre com no mínimo duas turmas do curso de Pedagogia. Desde 2019, ela é ofertada como disciplina eletiva para outras licenciaturas da UFRGS, por pedidos das Comissões de Graduação, o que vem aumentando o número de turmas. Porém não foram feitos concursos específicos, tampouco foi criada área própria, o que significa que a disciplina tem sido oferecida como novo encargo, somado aos já existentes, com acréscimo de atividade docente para alguns dos professores que a propuseram. Há uma demanda institucional, por conta da obrigatoriedade legal da ação afirmativa, porém a resposta à tal exigência ainda tem sido construída mais por indivíduos comprometidos e afetados com a promoção da igualdade racial do que pela universidade como coletividade organizada e com função social definida. Isso gera a compreensão de que são temas reservados a alguns ou ações voluntariosas de outros, quando de fato se trata de um dispositivo legal objetivo que não pode depender de subjetividades ou afetividades individuais.

Está no cerne dessa disciplina o conhecimento do ordenamento legal que regula a ERER no Brasil, bem como as aprendizagens necessárias para a mediação dos conflitos raciais na escola. Compreendemos que não basta o domínio dos conhecimentos sobre a história e a cultura de negros e indígenas se houver omissão, ignorância ou inoperância diante da ocorrência de conflitos e discriminações raciais dentro da sala de aula e nos demais ambientes escolares. Apontamos para o equívoco de imaginar que apenas a atribuição de estudo de temáticas correlatas ao artigo 26-A contemple o cumprimento dessa política pública.

Apontamos que já na súmula a disciplina tem um conteúdo centrado na promoção da igualdade racial, fato que a diferencia de outras, nas quais a questão racial é diluída em grandes temas, com Direitos Humanos ou Inclusão ou Diversidade, perdendo a especificidade da reparação histórica que a ação afirmativa se destina a realizar.

Destacamos o fato de que a implementação da disciplina se faz fora dos prazos do Plano Nacional de Implementação da ERER, que colocava tal iniciativa como uma meta de curto prazo, a ser alcançada entre 2009 e 2010. O Ministério Público já havia inquirido a UFRGS sobre a prática desse plano e tal pressão também favoreceu o cumprimento da legislação afirmativa do ponto de vista étnico-racial nos currículos. O debate interno e a fiscalização externa permanecem inconclusos e necessários no espaço acadêmico universitário.

Ao se tornar signatário da carta da Conferência de Durban (ONU, 2001) o Estado Brasileiro assumiu mundialmente "o compromisso de desenvolver ações afirmativas contra o racismo e a discriminação racial no campo da Educação" (MEINERZ, 2017, p. 241). Nesse contexto, o Plano Nacional de Implementação das DCNERER, com metas programadas para alcance entre 2009 e 2015, descreve o que é esperado das IES da seguinte forma:

Dedicar especial atenção aos cursos de licenciatura e formação de professores(as), garantindo formação adequada aos professores(as) sobre o ensino de História e Cultura Afro-brasileira e africana e os conteúdos propostos nas leis 10.639/08 e 11.645/08. (BRASIL, 2008, p. 40) 
Tal meta fora planejada como de curto prazo, a ser alcançada entre 2009/2010, no item assim descrito: "Incluir nas licenciaturas, com destaque para o curso de Pedagogia, temas relacionados à diversidade étnico-racial em seus currículos” (BRASIL, 2008, p. 65).

Em 2014, foi aprovado o Plano Nacional de Educação (metas estabelecidas de 2014 até 2024), articulado com o Plano Nacional de Implementação das Diretrizes Curriculares Nacionais para a Educação das Relações Étnico-Raciais, assim como o Plano Nacional de Educação em Direitos Humanos (2007), as Diretrizes Curriculares Nacionais para a Educação Escolar Quilombola (2012) e as Diretrizes Operacionais para a implementação da História e das culturas dos povos indígenas na Educação Básica (2015). Em todos esses planos estatais de ação há o destaque da necessidade de que os currículos de formação inicial dos professores atendam às prerrogativas legais do artigo 26-A, política de Estado e não apenas de governos.

A breve trajetória que narramos nos faz inferir que o processo de implementação da ERER, apesar das determinações do Estado, ainda se faz majoritariamente por ações de coletivos que se unem por afinidades e afetos com a causa antirracista, em ações mais voluntariosas do que em políticas institucionais, que revelem um compromisso com os Planos e Diretrizes Nacionais correlatas.

Pensemos os impactos dos dispositivos legais que orientam a ação afirmativa configurada na criação do artigo 26-A/LDBEN (2003), a partir da análise de registros documentais oriundos de algumas atividades propostas na disciplina e suas ressonâncias nos estudantes que nela se matriculam.

\section{Ressonâncias da Educação das Relações Étnico-Raciais como Disciplina Obrigatória: Observações a partir da Escuta de Estudantes}

Tornou-se consenso para quem estuda as ações afirmativas de promoção da igualdade racial no campo da Educação, o fato de que elas resultam de movimentos que se realizaram majoritariamente de fora para dentro das instituições, correlatas ao movimento negro e indígena organizado, especialmente a partir de 1978, momento de unificação e de pressão ao Estado brasileiro pelo combate ao racismo no País.

Observamos que os primeiros pesquisadores que estudaram e indicaram caminhos para a implementação do artigo 26-A foram justamente as intelectualidades negras que estavam em espaços de poder político e acadêmico, como Nilma Lino Gomes, Petronilha Beatriz Gonçalves e Silva, Kabengele Munanga. No caso que aqui analisamos não é diferente, temos também a presença de uma intelectual negra no protagonismo do processo.

Vejamos como a disciplina em consideração, na qualidade de implementação do artigo 26-A na Educação Superior, impacta e cria ressonâncias entre as(os) estudantes, a partir da obrigatoriedade curricular do estudo de história e cultura africana, indígena e afro-brasileira na formação docente inicial. A observação e análise de tais ressonâncias foi realizada em registros de avaliações escritas e expressões artísticas das(os) estudantes. Os resultados parciais demonstram as desestabilizações construídas ao longo dos estudos propostos, consoante os princípios da branquitude que hegemonizam a formação docente e compõem o ethos institucional da Educação Superior. Tais desestabilizações emergem de formas distintas entre estudantes, que notadamente se impactam diferentemente na relação com os estudos e propostas pedagógicas. Nesse processo, destacaremos a desconstrução de estereotipias e a desestabilização de subjetividades docentes no decorrer das práticas pedagógicas da disciplina.

As aulas e atividades da disciplina se desenrolam numa proposição de pensar de dentro para fora, trocando conhecimentos que partam de saberes de si, da sua ancestralidade, da sua comunidade. Inicia-se com a apresentação de cada estudante através de desenhos de autorretratos com as cores do giz de cera criado no 
Projeto de Extensão UNIAFRO/UFRGS (no ano de 2014), com doze tons de pele. Cada uma ou um deve se desenhar e se apresentar racialmente, contar da sua família e ancestralidade. Ali começam os momentos de desconforto, de não saber, de afirmar-se, de envergonhar-se. São momentos que a mediação pedagógica exige dizer sobre o que nos compõe como indivíduos, do racismo que nos estrutura tanto individualmente quanto institucionalmente, operando sobre nossas atitudes como educadores. Na sequência do plano de ensino, há a participação de convidados(as) com relatos de ações de ERER, em escolas ou projetos educativos. Questões registradas nas aulas são latentes, tais como: "como nomear a cor da minha pele?"; "posso falar a palavra negro?"; "como pessoa branca, posso falar sobre isso?"; "como tratar a questão religiosa africana e afro-brasileira em comunidades escolares onde o preconceito com as mesmas predomina?". No processo da disciplina é exigida a leitura e a resenha comentada das DCNERER, entre leituras de autores de referência, como Azoilda Loretto da Trindade, Nilma Lino Gomes, Petronilha Beatriz Gonçalves e Silva. Igualmente se faz obrigatória a construção grupal e o compartilhamento de planejamentos didáticos na perspectiva da ERER, processo que exige mediações teórico-metodológicas. Os grupos são orientados a construir sequências didáticas inovadoras e comprometidas com valores civilizatórios afro-brasileiros (TRINDADE, 2010).

Por valores civilizatórios afro-brasileiros compreendemos as práticas pedagógicas concebidas a partir de uma afro-brasilidade expressa em:

“[...] maneiras, possibilidades de matrizes africanas ressignificadas pelo modo de ser dos brasileiros/as" (TRINDADE, 2010, p. 13).

Vejamos um exemplo de mediação do planejamento: um grupo de estudantes desejava fazer um estudo e sequência didática orientada para a colonização e os movimentos de migração no Rio Grande do Sul. Esse grupo trouxe a narrativa hegemônica de uma colonização europeia e, no diálogo de mediação e de leituras, construiu um questionamento do vínculo entre racismo e colonialismo, assim como descobriu a possibilidade de nomear os "colonos africanos" como fundamentais no desenvolvimento do Rio Grande do Sul. Concluíram com a seguinte formalização para a construção dos conceitos associados à relação-problema de seu planejamento:

Conhecendo a história dos migrantes: nomear quem são, lembrar dos colonos africanos que vieram por migração forçada, mas vieram para trabalhar aqui como os demais. Conceitos destacados: Diversidade étnica; Origem das famílias da turma relacionada com a história local; Migração interna e externa; imigração; migração forçada.

Com essa sequência de aulas, em busca de positivar as histórias dos estudantes a pensar sobre suas próprias origens e também de sua família, pretendemos abordar uma introdução sobre a história dos imigrantes que moldaram a biografia, a cultura e a origem do Rio Grande do Sul, problematizando a posição étnica e cultural que foram implementadas pelos diversos povos durantes a migração. Escolhemos este tema a partir do intuito de construir uma relação étnicacultural baseada na diversidade. Desejamos que os estudantes compreendam mais sobre a própria origem e que possam valorizar os aspectos culturais mais importantes de cada povo migratório.

Cabe aqui refletir a desconstrução da estereotipia acerca da história do Rio Grande do Sul, estado onde o mito de origem - o Gaúcho - parece apenas ceder à hegemonia branca nas narrativas de origem ou fundacionais para o relato ficcional de uma exclusiva origem europeia, alemã ou italiana. Tal narrativa aborda a chegada dos imigrantes em meados do século XIX como $a$ invenção do estado e do desenvolvimento econômico, negando por completo a importância de outros processos históricos importantes, como a cultura do charque e do pastoreio, por exemplo, protagonizados por indígenas e negros, com seus saberes e técnicas. Tal estereótipo se ancora numa 
proposição colonial que impregna os currículos e que exige um processo de descolonização (GOMES, 2012).

As reflexões de Aimé Césaire (1978) sobre o projeto colonial empreendido pelos povos europeus sobre os povos de África e América questionam a humanidade possível para as múltiplas existências negras. Trata-se de um projeto civilizatório que coloca um padrão hegemônico com pretensão de validade universal e que se pauta pela morte daquele que está fora desse perfil, destacadamente negros e indígenas. Esse projeto é marcado pela violência. Vejamos:

Falo de milhões de homens arrancados aos seus deuses, à sua terra, aos seus hábitos, à sua vida, à vida, à dança, à sabedoria. Falo de milhões de homens a quem inculcaram sabiamente o medo, o complexo de inferioridade, o tremor, a genuflexão, o desespero, o servilismo. (CÉSAIRE, 1978, p. 25-26)

A ação afirmativa no campo do currículo, através do artigo 26-A/LDBEN, não nos permite mais ocultar essa violência que se reproduz pela repetição de uma história única, na qual o colonizador branco europeu é o centro do projeto de humanidade que ainda se sustenta como hegemônico.

Ainda na consideração de observar a construção de um currículo plural, do ponto de vista étnico-racial, destacamos outro planejamento que pretendia reflexionar sobre a multiplicidade religiosa e a valorização das religiões de matriz africana, trabalhando criticamente os "emojis" reproduzidos em mídias sociais. O grupo propôs a análise dos emojis com questões como: temos emojis que podem ser enquadrados como cristãos? Quais? Temos emojis que podem ser enquadrados como não cristãos? Quais? O plano aprofundava o debate e ao final propunha a criação de "emojis" com elementos da religiosidade de matriz africana. Nessa mediação, usou-se de um profundo debate e rompimento com estereótipos em relação às práticas religiosas não cristãs.

Outro coletivo optou por planejar algo para refletir sobre processos históricos vividos pelos povos indígenas originários, comparando a área ocupada pelos povos originários antes da colonização e atualmente, abordando as tradições de cada etnia indígena predominante no RS. Nessa mediação foi necessário o questionamento de palavras como tribo e índio, capaz de romper com as estereotipias do racismo cotidiano.

Apontamos que essas proposições sinalizam uma multiplicidade de sequências didáticas, construídas na formação inicial, para implementar a ERER nas diversificadas áreas do conhecimento. Um dos impactos nas(nos) estudantes trata do pensar criticamente a linguagem e a língua praticada no cotidiano escolar, como componentes igualmente colonizados capazes de operar com a continuidade do racismo e da supremacia branca. Segundo Grada Kilomba (2019, p. 14),

[...] é como se a língua, por mais poética que possa ser, tem também uma dimensão política de criar, fixar e perpetuar relações de poder e violência, pois cada palavra que usamos define o lugar de uma identidade. No fundo, através das suas terminologias, a língua informa-nos constantemente de quem é normal e de quem é que pode representar a verdadeira condição humana.

Problematizar os usos dos termos índio, colonos, migração, escravização, tribo, comunidade como termos que dizem de uma pluralidade de experiências e não de uma história única é desafio educativo que passa pela linguagem. Alguns impactos foram recolhidos de registros de participações em fóruns da disciplina e sinalizam movimentos de autorreflexão e desestabilização, seja pela observação de seu lugar de privilégio, seja pelo reconhecimento de sua trajetória de dores e superações individuais e coletivas.

Observamos o exercício de fala e escuta constante realizado nas atividades analisadas, destacando a emergência de sentimentos que se distinguem na complexidade do poder falar, uma vez que nem sempre 
o subalterno pode proferir sua palavra (SPIVAK, 2010). Um impacto que desestabiliza é, portanto, o falar sobre a questão racial, exercício que provoca controvérsias. Não se trata do ato de "falar em si", no sentido de conseguir articular a fala ou falar em seu próprio nome, mas da dificuldade de se expressar dentro do regime estruturado pelo racismo e pela branquitude. Assim, temos manifestações como:

\footnotetext{
Eu, como mulher branca, ao final de tudo isso, só conseguia pensar que eu nunca tive que passar por nenhuma situação como essa. Que sensação horrível. [...] Eu me senti fraca. O que eu escutei foi um gostinho amargo do que ele escutou, do que ele passou. E me senti fraca perante essa sociedade. Eu penso em como tenho que ser forte se eu quiser ser uma profissional boa na área da educação. Nem digo no sentido de sucesso na carreira, mas digo como pessoa. Um sucesso de pessoa. Como fica o meu interior? Como vou ensinar crianças a serem fortes e terem orgulho de si mesmas se a adulta aqui, não é?
}

A desestabilização da subjetividade com foco no debate inter-racial está vinculada ao alcance da própria escuta em ambientes colonizados, como é o caso da universidade, lócus da atuação disciplinar de ERER na formação docente. A ideia de ciência universal predominante no espaço acadêmico tende a preservar a supremacia branca, seja pelo silêncio dos que sempre falaram, seja pela fala dos que sempre silenciaram (KILOMBA, 2019). Reiteramos que conhecimento e poder racial estão intimamente ligados e observamos isso na ressonância do que é dito ou calado nos fóruns da disciplina.

A seguir, apresentaremos brevemente o processo de fiscalização do cumprimento do artigo 26-A nas redes de ensino da Educação Básica no Rio Grande do Sul.

\section{Caminhos de Implementação do Artigo 26-A/LDBEN como Obrigatoriedade nos Planos de Ensino da Educação Básica}

Implementar e fiscalizar o cumprimento do artigo 26-A em currículos escolares e universitários é o desejo de pesquisadores, professores e lideranças do movimento social negro. Ver nossos estudantes conhecendo de fato a história completa e qualificada do Brasil, aprendendo positivamente e equitativamente sobre todas as nossas ancestralidades e saberes é uma das contribuições dessa ação fiscalizatória. Na mudança construída a partir da interrogação sobre o lugar das relações étnicoraciais nos currículos, concretizada a partir da homologação da Lei 10.639/03, o debate epistemológico sobre o que seja a ciência é central. Para Boaventura de Sousa Santos (2009), toda possibilidade de mudança está relacionada à possibilidade de rejeitar a "monocultura do saber", isto é, recusar a ideia de que o único conhecimento legítimo é o eurocêntrico, o saber do Norte. A esse modo de pensar o mundo, o sociólogo denomina de razão indolente, modelo de racionalidade reprodutor de formas de pensar e viver a cidadania sem considerar experiências sociais que não as da modernidade ocidental, europeia e branca.

A análise dos dados do auditamento do TCE/RS evidencia a força da consolidação dessa espécie de razão indolente, na medida em que tais informações demonstram a sustentação de uma monocultura contínua e a inserção eventual de outros saberes como resposta cidadão a uma relevante inquirição, como a do artigo 26-A. Os dados revelam poucas ações contínuas, normatizadas e com destinação de verba pública para cumprimento da Lei. Até o presente momento, os saberes não ocidentais continuam em grande medida fora do debate do currículo escolar nas redes de ensino do Rio Grande do Sul. 
Vejamos como ocorreu o processo de fiscalização. Após um processo de formação e sensibilização junto aos gestores das redes de ensino, em março de 2015, o TCERS oficiou todas as prefeituras municipais, comunicando que:

[...] a partir do exercício de 2016, a Corte de Contas passaria a contemplar o cumprimento do artigo 26-A da LDB entre os itens obrigatórios de suas rotinas de fiscalização. (RIO GRANDE DO SUL, 2015, p. 2)

Os eixos da ação fiscalizatória (orçamento, formação, normativas), organizados no instrumento de fiscalização, como um questionário elaborado com a assessoria do GT 26-A, foram enviados às prefeituras municipais. Os resultados das respostas a esses questionários foram divulgados em dezembro de 2015, na forma de relatório apresentado em evento na sede do Tribunal e publicado no sítio do mesmo órgão. Na sequência, houve a tentativa de realizar auditorias in loco em alguns municípios, por amostragem, para observar se o respondido no instrumento consistia em práticas com comprovação documental. Nos anos seguintes, o TCE/ RS permanece incluindo o artigo 26-A nas rotinas de inquisição das ações e contas dos municípios gaúchos.

$\mathrm{Na}$ análise aqui empreendida, trataremos os dados do eixo fiscalizatório, que buscava as normativas construídas para a implementação da Lei, especificamente a reformulação dos projetos político-pedagógicos (PPP) das unidades de gestão escolar. Para compreendermos os resultados sobre tal eixo, é necessário observar que, na primeira fiscalização do tribunal, realizada em 2015, 483 municípios deram retorno; já em 2018, 489 municípios participaram. O Rio Grande do Sul possui um total de 497 municípios.

Nos questionários da fiscalização, há uma questão central que consideramos ser o fio condutor de todas as demais questões, pois ela indaga aos munícipios se há implementação ou não da Lei, inquirindo justificativas. Destacamos algumas justificativas com as razões que levaram à não implementação. Em 2015, as justificativas foram: planos estão em processo de elaboração; não consta no regimento e nos planos de ensino, em função de a região não possuir moradores com as culturas e histórias afro-brasileiras e indígenas; falta de recursos didáticos, pedagógicos e financeiros; falta de formação adequada para os professores. Já em 2018, transcorridos quatro anos, as explicações para a não implementação seguiram praticamente as mesmas. Permanece, na leitura e interpretação dessas respostas, o silêncio no ar, o aperto no coração e a indignação profunda. Nossa análise anterior já apontou para as questões da formação inicial de professores como parte do cumprimento da Lei que cabe às IES, mas a formação continuada é igualmente compromisso das gestões locais de educação, inclusive em parceria com o movimento social e com as universidades, conforme as DCNERER.

Vejamos a seguir as respostas que reconhecem o cumprimento da obrigação legal. Apresentamos as Figs. 1-3, compilados no relatório do TCE-RS (RIO GRANDE DO SUL, 2015):

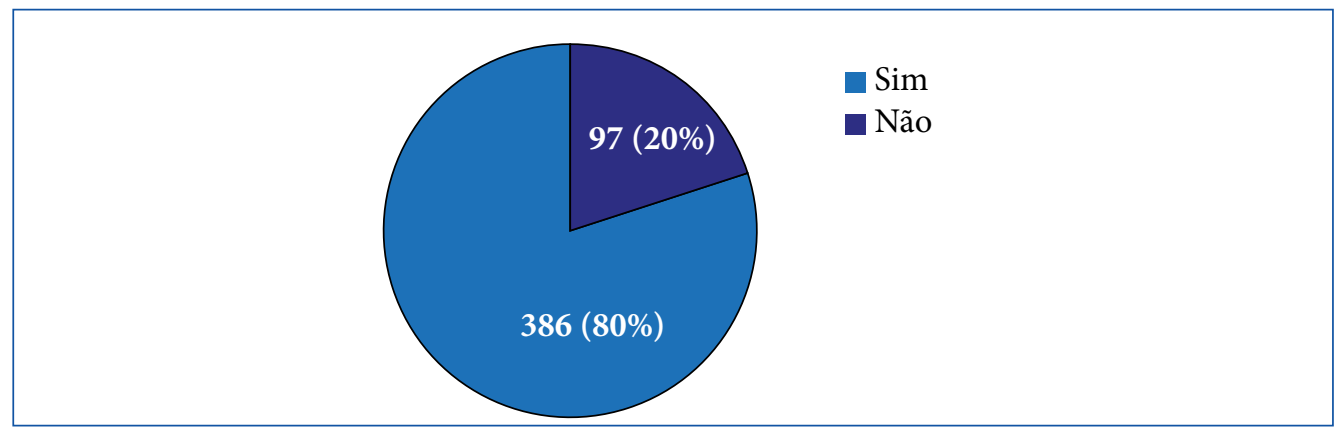

Fonte: Extraído de Rio Grande do Sul (2015). Figura figura com modificação na cor e apresentação da porcentagem dos dados, dados de livre acesso e com permissão de uso.

Figura 1. Nos projetos pedagógicos apresentados pelas escolas está incluído, conforme previsto no artigo 26-A da LDB, o ensino das histórias e culturas africanas? 
Nos PPPs está incluído, conforme artigo 26-A da LDB, o ensino das histórias e culturas africanas em $80 \%$ dos municípios (386). Ao contrário, 20\% dos municípios (97) não incluem tal obrigação legal.

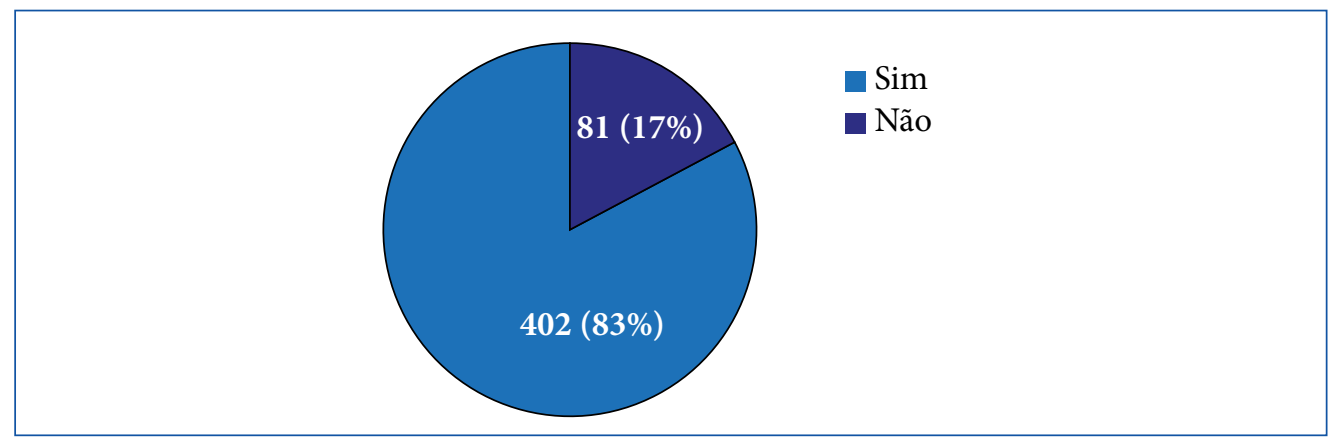

Fonte: Extraído de Rio Grande do Sul (2015). Figura figura com modificação na cor e apresentação da porcentagem dos dados, dados de livre acesso e com permissão de uso.

Figura 2. Nos projetos pedagógicos apresentados pelas escolas está incluído, conforme previsto no artigo 26-A da LDB, o ensino das histórias e culturas afro-brasileiras?

Com relação ao ensino das histórias e culturas afro-brasileiras, 83\% dos municípios (402) declararam que, nos projetos de suas escolas, contempla-se tal conteúdo. Os que responderam que não está incluído em seus projetos representam $17 \%$ dos municípios (81).

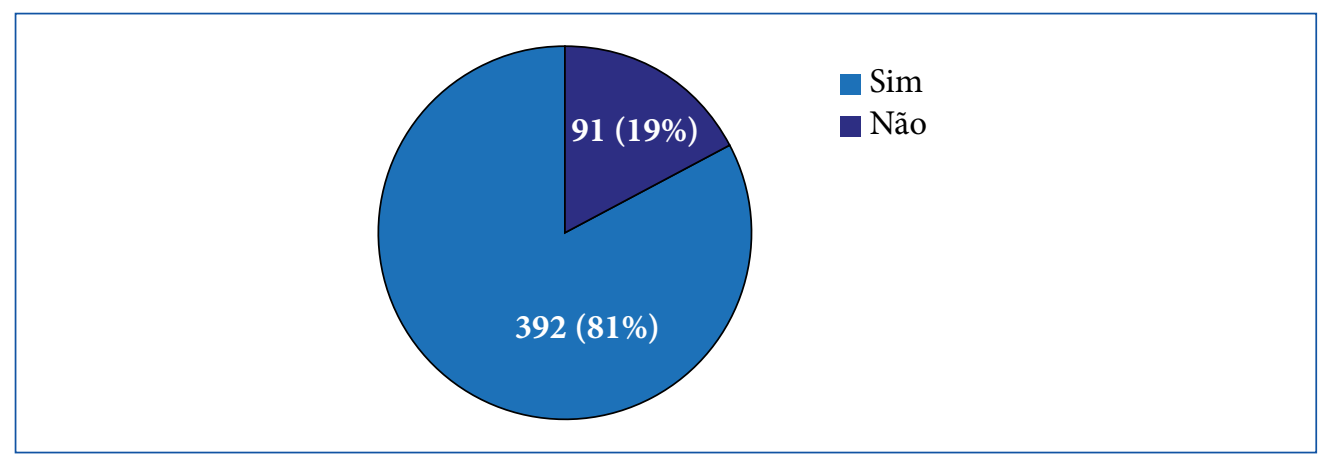

Fonte: Extraído de Rio Grande do Sul (2015). Figura figura com modificação na cor e apresentação da porcentagem dos dados, dados de livre acesso e com permissão de uso.

Figura 3. Nos projetos pedagógicos apresentados pelas escolas está incluído, conforme previsto no artigo 26-A da LDB, o ensino das histórias e culturas indígenas?

Quando se tratou do ensino das histórias e culturas indígenas, 81\% dos municípios (392) declararam que, nos projetos de suas escolas, está sendo contemplado tal ensino conforme a Lei. Os que ainda não incluíram correspondem a 19\% dos municípios (91).

Nos resultados da auditoria realizada em 2018, no que se refere aos PPPs, o ensino das histórias e culturas africanas é contemplado em 392 dos municípios, enquanto 97 responderam que não cumprem tal obrigação. O ensino das histórias e culturas afro-brasileiras é realizado em 447 municípios, enquanto 42 não cumprem a Lei. Já em relação ao ensino das histórias e culturas indígenas, 423 municípios retornaram o questionário dizendo que contemplam essa prerrogativa, sendo apenas 66 os municípios que não contemplam a Lei. Os resultados informados em 2015 e 2018, nas auditorias realizadas pelo TCE/RS (RIO GRANDE DO SUL, 2015; 2018), apresentam um pequeno aumento de municípios que garantem, em seus projetos pedagógicos nas escolas, o ensino das histórias e culturas africanas, afro-brasileiras e indígenas. 
Ao contrapor tais informações com outras perguntas do instrumento, observamos que os municípios, ao explicitarem de que forma estão garantindo as práticas prescritas nos projetos pedagógicos, mencionaram que as temáticas foram abordadas de forma pontual ao longo do ano letivo, citando como exemplo a prática de inserção do assunto no ensino em itens como Dia da Consciência Negra ou Dia do Índio. Tal resposta aponta para a possível incompreensão do que está posto nas DCNERER, na qualidade de ações contínuas e aprofundadas de transformação do currículo escolar, ao longo de todo o ano e em todas as atividades de ensino e aprendizagem.

Ressaltamos que há índices reduzidos ou inexistentes de investimento em formações continuadas. Os dados apresentados pelo TCE-RS, em 2015, já sinalizavam ausências, explicitando que 298 municípios declararam ter oferecido formação específica sobre o artigo 26-A aos professores nos últimos cinco anos, enquanto 185 responderam que não (RIO GRANDE DO SUL, 2015). Segundo o relatório do TCE/RS:

[...] a pesquisa demonstrou que somente $62 \%$ dos respondentes informaram ter realizado formação específica para professores sobre a temática em pauta nos últimos cinco anos. E, entre os que dizem oferecer treinamentos, inferiu-se das respostas qualitativas obtidas que muitos realizam eventos genéricos e ações pontuais, carecendo os Municípios de uma política de formação. Fica evidente, portanto, a necessidade de se colocar o tema nas agendas escolares com maior relevância (RIO GRANDE DO SUL, 2015).

Os dados exponenciam uma espécie de máscara do silenciamento, conforme Grada Kilomba (2019), construídas nas respostas dos gestores da Educação Básica, reiterando o silêncio sistêmico acerca dos conhecimentos das histórias e culturas africanas, afro-brasileiras e indígenas nas agendas das redes de ensino. A inserção de elementos, nas respostas ao instrumento fiscalizatório, com o intento de comprovar o cumprimento dos dispositivos legais, tais como referências literárias e teóricas nos planos, registros de atividades nas aulas de Artes, eventos celebrativos do 20 de novembro, apenas silencia sobre a manutenção das mesmas práticas, com pontuais acréscimos e sem aprofundamento das mudanças epistemológicas inquiridas no artigo 26-A, em sua devida correlação com os diversos campos do currículo. Observa-se que tal mascaramento do cotidiano de fato aplicado impede avanços, pois leva a um movimento de pouco reconhecimento de práticas endógenas a serem superadas e em responsabilização de práticas exógenas, no caso a falta de formação na Educação Superior.

As universidades precisam contribuir em sua função social, qualificando a formação inicial dos professores com o conhecimento científico acerca das culturas até então ausentes e negligenciadas nos currículos, mas a formação continuada segue sendo corresponsabilidade dos gestores locais. Nesse sentido, os currículos passam a ser um território de disputa para o efetivo cumprimento da legislação que impõe a ERER. O que observamos, participando do GT 26-A, é que, diante desses retornos apresentados pelos municípios gaúchos, fica evidente a lógica racista, seja institucional ou estrutural. Os privilégios, mantidos ao longo da história pela branquitude, permanecem, tornando a implementação da legislação antirracista, por vezes, ineficaz. Com o descumprimento sistemático, estados, municípios e estabelecimentos privados violam os direitos dos estudantes, no que compete ao artigo 26-A.

Os dados da fiscalização nos fazem apontar parcialmente para o fato de que os gestores, na falta de comprovação de atuação efetiva e planejada no que tange à formação, à normatização e à aplicação de recursos orçamentários, respondem com ações pontuais, em geral realizadas por pessoas afetadas politicamente com o combate ao racismo na Educação, ou organizadas apressada e voluntariosamente, sem compromisso institucional contínuo. 


\title{
Considerações Finais
}

\author{
Asfixia \\ Eu queria, assim, bem simplesmente, \\ Fechar os meus olhos e celebrar \\ A lembrança do filho correndo pro mar \\ mas há uma tensão constante \\ Um ranger de dentes \\ Será porque matam minha gente \\ Impunemente $[\ldots]$ \\ (RICARDO, 2019, p. 71)
}

O sentimento tenso da asfixia, descrito poeticamente na epígrafe acima, inspira a análise acerca da ERER na formação inicial proposta para educadores que vão atuar na Educação Básica, enfatizando a observação das tensões contidas na presença de corpos negros na escola (GOMES, 2017) e as questões que geram quando frágeis, na tenra primeira idade, quando precisam ser cuidados, trocados, ninados, acariciados. São os filhos de mães negras que sofrem da asfixia por não saberem como serão cuidadas e miradas suas crias quando fora de casa.

Destacamos que nossa escrita não está comprometida apenas com a compreensão do tema em exame, está igualmente circunscrita na adesão ao projeto político e pedagógico de erradicação do racismo na sociedade brasileira. A asfixia diante das injustiças causadas pelo racismo move esta redação conjunta. Compreendemos que essa erradicação passa necessariamente pelo compromisso formativo e fiscalizador que sociedade e instituições de formação precisam assumir. O compromisso formativo se conecta com o artigo 26-A/LDBEN e sua respectiva regulamentação (BRASIL, 2004), na medida em que responsabiliza a Educação Superior acerca da função social de promover formação inicial comprometida com o combate ao racismo e com a promoção da equidade racial.

Aquela criança que, em 2003, iniciou no primeiro ano do Ensino Fundamental, provavelmente concluiu o Ensino Médio sem os conteúdos e atividades que sabidamente seriam importantes para sua formação, principalmente no que tange ao combate ao racismo. Consideramos que as instituições, como escolas e universidades, são responsáveis por romper com esse ciclo que "faz com que a cultura, aparência e as práticas de poder de um determinado grupo tornem-se o horizonte civilizatório do conjunto da sociedade" (ALMEIDA, 2018, p. 31). As brechas nascem de movimentos e disputas, como os que destacamos aqui: a fiscalização e a consolidação de formação acadêmica obrigatória em perspectiva de ERER.

A ERER é aqui compreendida enquanto "projeto para a sociedade brasileira, assumido como política de Estado no ano de 2003” (MEINERZ, 2017, p. 242), desdobrada para o campo da Educação e do Currículo a partir da criação do artigo 26-A/LDBEN. Destacamos que:

[...] o Brasil é signatário de acordos internacionais de combate ao racismo, portanto mudanças de governo não devem implicar no abandono dessa plataforma estatal. Enquanto projeto, atinge toda a sociedade e não se resume às políticas públicas curriculares, pois pressupõe mudanças nas práticas socioculturais cotidianas. Tal política de Estado em vigência no nosso país justifica-se num contexto de reparação histórica que atende ao reconhecimento de que nossa sociedade, através de seus gestores, cometeu crimes gravíssimos no passado (escravização, impedimento de acesso à terra, trabalho e escola), causando uma assimetria do ponto de vista étnico-racial (MEINERZ, 2017, p. 242). 
Ao estarmos num espaço de interseção entre a Escola e a Universidade, num grupo responsável pela fiscalização da ação afirmativa de implementação do artigo 26-A da LDBEN, observamos as contradições de nossa própria IES, que ainda responde de forma incompleta às demandas sociais e aos dispositivos legais de promoção da igualdade racial em nosso país. Estamos fora dos prazos estabelecidos pelas metas do Plano Nacional de ERER para a formação docente dos profissionais da Educação, porém estamos analisando processos já realizados como alternativas para seguir aprofundando o projeto da educação antirracista no Brasil. Esse movimento de autorreflexão indica que reconhecer equívocos é mais eficaz do que mascarar ou silenciar diante de práticas de descumprimento do artigo 26-A.

Destacamos a possível relação existente entre a pertença racial dos gestores e a implementação e a fiscalização dos dispositivos legais que regulam a ERER nas instituições de ensino. Dados do IBGE (2019, p. 28), sobre pertença racial dos gestores, revelam que

[...] enquanto a diferença por cor ou raça se torna mais acentuada com o aumento da população, isto é, nos municípios de maior porte populacional, observa-se preponderância de gestores de cor ou raça branca.

Esse não é um dado novo, pois o estudo de Shirley Aparecida de Miranda e de Rodrigo Ednilson de Jesus (2012) sobre a institucionalização da Lei 10.639/03 já apontava que a permanência do legado cultural escravocrata e patriarcal ainda mantinha sérias repercussões no acesso às instâncias de poder e decisão e nos cargos públicos. Tal estudo foi reconfigurado com o estado da arte publicado seis anos mais tarde (SILVA; RÉGIS; MIRANDA, 2018).

A análise dos dados aqui empreendida explica, em parte, a lentidão e a ineficácia na efetivação da ERER na Educação Básica e Superior, uma vez que observa a operacionalidade do racismo institucional e constata que a branquitude não está de fato implicada na efetivação do artigo 26-A.

Finalmente, reiteramos que nossas reflexões pontuam o racismo que estrutura a instituição educativa e se expressa na ação de gestores que pouco assumem o artigo 26-A/LDBEN como ação afirmativa e política de Estado, a ser implementada, no campo do currículo, não apenas por ações individuais e voluntariosas, mas por planos e grupos institucionais organizados. Os gestores tendem a se utilizar, em momentos de pressão externa e de fiscalização, de exemplos advindos de ações individuais e não institucionais. No que tange às ações afirmativas, na qualidade de obrigatoriedade curricular do aprendizado inter-racial na formação docente, consideramos que o desafio está posto, pois os dados mostram que é um direito a ser reafirmado em aliança com todos os setores e instituições democráticas do País.

\section{Contribuição dos autores}

Problematização e Conceituação: Meinerz, C.B.; Kaercher, G.E.P.S; Rosa, G.O.N.; Metodologia: Meinerz, C.B.; Kaercher, G.E.P.S; Rosa, G.O.N.; Análise: Meinerz, C.B.; Kaercher, G.E.P.S; Rosa, G.O.N.; Redação: Meinerz, C.B.; Kaercher, G.E.P.S; Rosa, G.O.N.

\section{Notas}

1. O GT se constituiu com um caráter interdisciplinar e interinstitucional, reunindo profissionais da área do Direito, Economia, Contabilidade, História, Sociologia e Educação, e de diferentes instituições públicas: Tribunal de Contas 
do Estado do Rio Grande do Sul, Ministério Público de Contas do Estado do Rio Grande do Sul, Centro de Apoio Operacional em Direitos Humanos do Ministério Público Estadual, Associação dos Procuradores do Estado do Rio Grande do Sul, Rede Afro-Gaúcha de Profissionais do Direito, Comissão de Direitos Humanos da Ordem dos Advogados do Brasil, Defensoria Pública da União, Faculdade de Educação da Universidade Federal do Rio Grande do Sul, Departamento de Educação e Desenvolvimento Social da Universidade Federal do Rio Grande do Sul e professores convidados, com destaque para a participação da professora aposentada Vera Neusa Lopes, reconhecida por sua trajetória no estudo e defesa dos temas apontados pelas Leis (TERRA, 2012).

\section{Referências}

ALMEIDA, S. L. de. O que é Racismo estrutural? Belo Horizonte: Letramento, 2018.

ALVES-BRITO, A. Os corpos negros: Questões étnico-raciais, de gênero e suas intersecções na física e na astronomia brasileira. Revista da ABPN, Goiânia, v. 12, n. 34, p. 816-840, 2020. https://doi.org/10.31418/21772770.2020.v12.n.34.p816-840

BENTO, M. A. S. Branqueamento e branquitude no Brasil. In: CARONE, I.; BENTO, M. A. S. (Orgs.). Psicologia social do racismo: estudos sobre branquitude e branqueamento no Brasil. Petrópolis: Vozes, 2002. p. 25-58.

BRASIL. Ministério da Educação. Lei n. 10.639 de 9 de janeiro de 2003. Altera a Lei no 9.394, de 20 de dezembro de 1996, que estabelece as diretrizes e bases da educação nacional, para incluir no currículo oficial da rede de ensino a obrigatoriedade da temática "história e cultura afro-brasileira" e dá outras providências. Diário Oficial da União, Brasília, 2003. Disponível em: https://legislacao.presidencia.gov.br/atos/?tipo=LE I\&numero=10639\&ano=2003\&ato=431MTTq10dRpWTbf4. Acesso em: 20 jul. 2021.

BRASIL. Ministério da Educação; Conselho Nacional de Educação. Parecer CNE/CP n. 003/2004 de 10 de março de 2004. Diretrizes Curriculares Nacionais para a Educação das Relações Étnico-Raciais e para o Ensino de História e Cultura Afro-Brasileira e Africana. Diário Oficial da União, Brasília, 2004. Disponível em: http://portal.mec.gov.br/cne/arquivos/pdf/003.pdf. Acesso em: 20 jul. 2021.

BRASIL. Ministério da Educação. Lei n. 11.645 de 10 de março de 2008. Altera a Lei no 9.394, de 20 de dezembro de 1996, modificada pela Lei no 10.639, de 9 de janeiro de 2003, que estabelece as diretrizes e bases da educação nacional, para incluir no currículo oficial da rede de ensino a obrigatoriedade da temática “História e Cultura Afro-Brasileira e Indígena”. Diário Oficial da União, Brasília, 2008. Disponível em: https://legislacao.presidencia.gov.br/atos/?tipo=LEI\&numero=11645\&ano=2008\&ato=dc6QTS61UNRpW Tcd2. Acesso em: 20 jul. 2021.

CARNEIRO, A. S. A construção do outro como não-ser como fundamento do ser. 2005. Tese (Doutorado em Educação) - Universidade de São Paulo, São Paulo, 2005.

CÉSAIRE, A. Discurso sobre o colonialismo. Lisboa: Livraria Sá da Costa Editora, 1978.

COELHO, M. C.; COELHO, W. de N. B. Educação para as Relações Étnico-Raciais e a formação de professores de História nas novas diretrizes para a formação de professores! Educar em Revista, Curitiba. v. 37, e77098, 2021. https://doi.org/10.1590/0104-4060.77098 
FONTOURA, M. C. L. Invasão / ocupação da UFRGS: diálogo com docentes de cursos de licenciaturas sobre Programa de Ações Afirmativas e Educação das Relações Étnico-Raciais - ERER. 2017. Tese (Doutorado em Educação) - Universidade Federal do Rio Grande do Sul, Porto Alegre, 2017.

GOMES, N. L. Relações étnico-raciais, educação e descolonização dos currículos. Currículo sem Fronteiras, v. 12, n. 1, p. 98-109, 2012.

GOMES, N. L. O movimento negro educador: saberes construídos nas lutas por emancipação. Petrópolis: Vozes, 2017.

GOMES, N. L. Prefácio. In: DORNELES, D. R.; PORCIUNCULA, V. R.; PIRAJIRA, T.; COSTA, C. da S.; EVANGELISTA, L. de O.; MEINERZ, C. B.; MOSSI, C. P. Reafirmando direitos: cotas, trajetórias e epistemologias negras e quilombolas na Pós-Graduação. Porto Alegre: CirKula, 2020.

GUIMARÃES, A. S. A. Modernidades negras: a formação racial brasileira (1930-1970). São Paulo: Editora 34, 2021.

INSTITUTO BRASILEIRO DE GEOGRAFIA E ESTATÍSTICA (IBGE). Perfil dos Municípios Brasileiros/2018. Rio de Janeiro: IBGE, 2019.

KILOMBA, G. Memórias da Plantação: episódios de racismo cotidiano. Rio de Janeiro: Cobogó, 2019.

MEINERZ, C. B. Educação e direitos humanos: especificidades das relações étnico-raciais no Brasil. Educação em Análise, v. 2, n. 2, p. 231-250, 2017.

MEINERZ, C. B.; RAMÍREZ, M. J. F. Educação antirracista e epistemologias diversas: políticas afirmativas no Brasil e Uruguai. Revista Educação e Cultura Contemporânea, v. 15, n. 39, p. 375-396, 2018. https://doi. org/10.5935/2238-1279.20180039

MEINERZ, C. B.; SANTOS, P. de S., PEREIRA, P. N. Branquitude, racismo e sexismo em docências realizadas por mulheres negras no ensino de história. ODEERE, v. 6, n. 1, p. 109-137, 2021. https://doi.org/10.22481/ odeere.v6i01.8535

MIRANDA, S. A.; JESUS, R. E. O processo de institucionalização da lei no 10.639/03. In: GOMES, N. L. (Org.). Práticas pedagógicas de trabalho com relações étnico-raciais na escola na perspectiva da Lei $\mathbf{n}^{\circ}$ 10.639/03. Brasília: MEC; Unesco, 2012. p. 47-71.

ORGANIZAÇÃO DAS NAÇÕES UNIDAS (ONU). Declaração e Programa de Ação. In: CONFERÊNCIA MUNDIAL DE COMBATE AO RACISMO, DISCRIMINAÇÃO RACIAL, XENOFOBIA E INTOLERÂNCIA CORRELATA, 3., 2001, Durban. Anais [...] Durban, ONU, 2001.

PEREIRA, A. A.; SILVA, J. R. S. Possibilidades na luta pelo ensino de histórias negras na era das bases nacionais curriculares no Brasil e nos Estados Unidos: a Lei 10.639/03 e os National History Standards. Educar em Revista, Curitiba. v. 37, e77098, 2021. https://doi.org/10.1590/0104-4060.76993

RIBEIRO, D. O que é lugar de fala? Belo Horizonte: Letramento, 2017.

RICARDO, D. Asfixia. In: OLIVEIRA, K. (Org.). Raízes, Resgate Ancestral: Antologia Poética. Belo Horizonte: Venas Abiertas, 2019.

ROSA, G. O. N. História que a História Não Conta. 2020. Dissertação (Mestrado em Educação) Universidade Federal do Rio Grande do Sul, Porto Alegre, 2020. 
SANTOS, B. de S. A crítica da razão indolente: contra o desperdício da experiência. 7. ed. São Paulo: Cortez, 2009.

SILVA, P. V. B.; RÉGIS, K.; MIRANDA, S. A. de (Orgs.). Educação das relações étnico-raciais: o estado da arte. Curitiba: NEAB-UFPR e ABPN, 2018.

SILVA, P. B. G. Entre o Brasil e a África: construindo conhecimentos e militância. Belo Horizonte: Mazza Edições, 2011.

SPIVAK, G. C. Pode o subalterno falar? Belo Horizonte: Editora UFMG, 2010.

RIO GRANDE DO SUL. Tribunal de Contas do Estado. Relatório Fiscalização do Cumprimento do Artigo 26-A da LDBEN nas escolas municipais do RS. Obrigatoriedade do ensino de história e cultura afrobrasileira e indígena. Diagnóstico TCE-RS. Porto Alegre: TCERS, 2015.

RIO GRANDE DO SUL. Tribunal de Contas do Estado. Relatório Fiscalização do Cumprimento do Art.26-A da LDBEN nas escolas municipais do RS. Diagnóstico TCE-RS. Obrigatoriedade do ensino de história e cultura afro-brasileira e indígena. Diagnóstico TCE-RS. Porto Alegre: TCERS, 2018.

TRINDADE, A. L. Valores Civilizatórios e a Educação Infantil: uma contribuição afro-brasileira. In: BRANDÃO, A. P.; TRINDADE, A. L. da (Orgs.). Modos de Brincar: caderno de saberes, fazeres e atividades. Rio de Janeiro: Fundação Roberto Marinho, 2010.

VERRANGIA, D. A formação de professores de ciências e biologia e os conhecimentos tradicionais de matriz africana e afro-brasileira. Revista Internacional de Investigación en Educación, v. 6, n. 12, p. 105117, 2013. Disponível em: https://revistas.javeriana.edu.co/index.php/MAGIS/article/view/7205. Acesso em: 20 jul. 2021.

\section{Sobre os autores}

Carla Beatriz Meinerz é lincenciada em História pela Universidade Federal do Rio Grande do Sul (UFRGS). Doutorado em Educação pela UFRGS. Docente no Departamento de Ensino e Currículo e no Programa de Pós-graduação em Educação da Faculdade de Educação da UFRGS, Linha de Pesquisa Educação Culturas e Humanidades. Membro do Grupo Interinstitucional GT 26-A do TCE/RS.

Gládis E.P. Da Silva Kaercher é licenciada em Letras pela Universidade Federal do Rio Grande do Sul (UFRGS). Doutora em Educação pela UFRGS. Docente no Departamento de Estudos Especializados e no Programa de Pós-graduação em Educação da Faculdade de Educação da UFRGS, Linha de Pesquisa Educação Culturas e Humanidades. Membro do Grupo Interinstitucional GT 26-A do TCE/RS.

Graziela Oliveira Neto Da Rosa é licenciada em Educação Física pela Universidade Luterana do Brasil (ULBRA) e em Pedagogia pelo Instituto Superior de Educação Equipe. Especialista em Gestão Escolar pela Faculdade Guilherme Guimbala da Associação Catarinense de Ensino. Professora na rede municipal de Esteio -RS. Estudante de Mestrado no Programa de Pós-graduação em Educação da Faculdade de Educação da UFRGS, Linha de Pesquisa Educação Culturas e Humanidades. Membro do Grupo Interinstitucional GT 26-A do TCE/RS. 